Estimating Marginal Cost of Quality Improvements: The Case of the UK Electricity Distribution Companies

\author{
Tooraj Jamasb, Luis Orea and Michael G. Pollitt
}

September 2010

CWPE 1052 \& EPRG 1027 


\title{
Estimating Marginal Cost of Quality Improvements: The Case of the UK Electricity Distribution Companies
}

\author{
EPRG Working Paper 1027
}

Cambridge Working Paper in Economics 1052

\section{Tooraj Jamasb, Luis Orea and Michael G. Pollitt}

Abstract

\begin{abstract}
The main aim of this paper is to develop an econometric approach to estimation of marginal costs of improving quality of service. We implement this methodology by way of applying it to the case of the UK electricity distribution networks. The estimated marginal costs allow us to shed light on the effectiveness of the current UK incentive regulation to improve quality, and to derive optimal quality levels and welfare losses due to sub-optimal quality levels. The proposed method also allows us to measure the welfare effect of the observed quality improvements in the UK between 1995 and 2003. Our results suggest that while the incentive schemes established by the regulator to encourage utilities to reduce network energy losses leads to improvement in sector performance, they do not provide utilities with sufficient incentives to avoid power interruptions. We find that the observed improvements in quality during the period of this study only represented $30 \%$ of the potential customer welfare gains, and hence there was still significant scope for quality improvements.
\end{abstract}

Keywords

JEL Classification

Contact

Publication

Financial Support
Electricity distribution cost, marginal cost, quality service, and social welfare

L51, L94

T.Jamasb@hw.ac.uk

September 2010

ESRC, TSEC1
$\mathrm{E} \cdot \mathrm{S} \cdot \mathrm{R} \cdot \mathrm{C}$

ECONOMIC

\& SOCIAL

RESEARCH COUNCIL 


\title{
Estimating Marginal Cost of Quality Improvements: The Case of the UK Electricity Distribution Companies *
}

\author{
Tooraj Jamasb \\ Department of Economics, Heriot-Watt University \\ Luis Orea \\ Visiting Scholar at Faculty of Economics, University of Cambridge \\ and \\ Department of Economics, University of Oviedo \\ Michael Pollitt \\ ESRC Electricity Policy Research Group \\ and \\ Judge Business School, University of Cambridge
}

22 September 2010

* The authors would like to acknowledge support from ESRC Electricity Policy Research Group, University of Cambridge 


\section{Introduction}

Since the 1990s, many regulators of infrastructure industries around the world have implemented incentive-based regulation models that mimic market mechanisms and promote efficiency improvements in natural monopolies. Such schemes have in particular been adopted in the regulation of electricity transmission and distribution networks (Jamasb and Pollitt, 2001). Service quality is an important attribute of electricity distribution for residential, commercial and industrial customers as many functions of the modern society depend on electricity. The incentive schemes incentivize the network utilities to undertake cost savings. However, the striving for cost savings may result in lower service quality as maintaining or improving upon a given level of quality of service is costly (see Ter-Martirosyan, 2003). The likely effects of traditional incentive regulation on service quality has recently attracted regulators' interest and a number of electricity regulators have made considerable effort to design incneitve regulation mechanisms for quality of service in electricity transmission and distribution networks (see Yu et al., 2009a).

In an ideal competitive electricity market, the socio-economic optimum occurs at a quality level where the sum of the total cost of quality provision by the network and the total quality induced costs to consumers is minimized. However, in the absence of (incentive) regulation, distribution companies may operate at suboptimal quality and social cost levels. In principle, the companies should be incentivized to provide the optimal quality level - i.e. where the marginal benefit of an extra unit of quality received by the customer is equal to its marginal cost (Ajohia et al., 2005). As shown in Figure 1, ineffective incentives might result in under-supply or over-supply of quality, and higher or lower than optimum levels of quality will result in welfare losses.

Figure 1. WTP, marginal costs and optimal quality levels

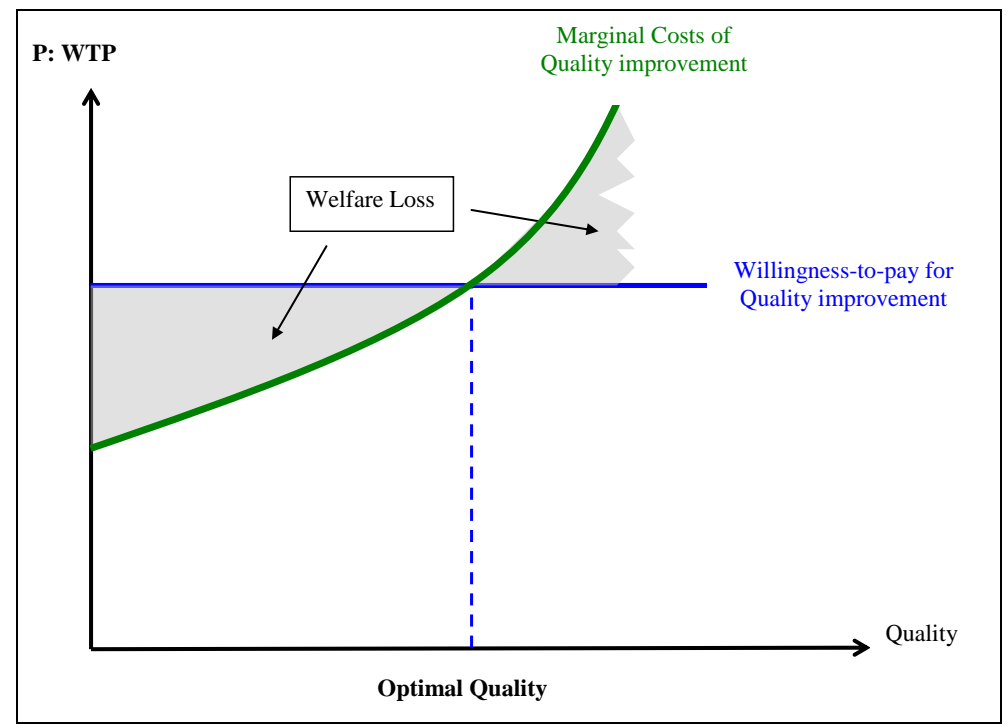


Sappington (2005) concludes that there are no simple policy solutions for effective regulation of quality of service but they depend on the information available to the regulator on consumer preferences and production technologies. Indeed, in designing quality-incorporated regulatory mechanisms, regulators are faced with the task of determining a market demand curve for service quality (i.e. the price customers are willing to pay for quality) and marginal cost of quality improvements. On the demand side, several studies have attempted to quantify the value of service reliability using the direct costs incurred by customers from service interruptions (Allan et al., 1999; Kariuki et al., 1996) or estimation of the consumers willingness-to-pay (WTP) to avoid power interruptions (Yu et al. 2009a). On the cost side, while previous papers have incorporated WTP and quality of service variables in non-parametric regulatory benchmarking (Giannakis et al., 2005; and Yu et al. 2009a, 2009b), marginal cost of quality improvements were not explicitly estimated. While the non-parametric approach to measure firms' efficiency does not provide information about the production characteristics or cost frontier, except for the returns to scale nature of the technology, aggregate inefficiency scores that include inefficient quality allocation can be obtained.

Previous studies have showed that utilities respond to quality of service incentives (Jamasb and Pollitt, 2007; Tangeras, 2009). However, in order to provide regulated utilities with proper reward and penalty for service quality it is crucial to have information on other technology characteristics and in particular on marginal costs of quality improvement. Indeed, the marginal cost of quality improvement can be viewed as a lower bound for setting incentive targets, as basing rewards or penalties merely on marginal benefit of improvement may provide utilities with overly generous incentive for socially efficient quality improvement. Hence, the aim of this paper is to estimate econometrically marginal costs of improving quality services of the UK electricity distribution utilities, and to shed light on the effectiveness of the current incentives to improve quality. Moreover, estimates of marginal costs indicate how far the utilities are from their optimal quality level (given the marginal benefit of quality improvement) and allow for computing welfare losses due to sub-optimal quality. We also measure the effect on welfare of quality improvements in the UK.

Section 2 introduces the empirical model and discusses several theoretical and econometrical issues concerning the estimation of marginal costs. Section 3 describes the data and variables used in the empirical exercise. Section 4 presents the parameter estimates using different specifications and estimators. Section 5 summarizes the results, and presents the main conclusions.

\section{Specification of the empirical model}

In this section we specify an empirical model to estimate marginal costs of improving quality service and apply this to case of the UK electricity distribution companies. 
An important issue to address is that, while accurate information about operational and capital costs and quality services might be available, the explanatory variable i.e. the marginal cost of quality improvements, is not observed. However, although we cannot estimate the marginal cost function directly, it may be inferred from previous estimations of the utilities' cost function. This means that while we can estimate "reasonably well" the cost level of a particular utility, the inferred marginal costs are less accurate - i.e. the confidence intervals and prediction errors are larger than in the cost function. ${ }^{1}$ The basic cost function to be estimated can be written as:

$$
\ln C=\ln C(y, n, e, q, t)
$$

where $C$ is a measure of utility costs, $y$ is the energy delivered, $n$ is the network length, $e$ stands for network energy losses, and $q$ is a measure of service quality (measured by the customers minutes lost), and $t$ is a time trend. ${ }^{2}$ We include network length to reflect the size of service area and network and has been used (as an output of networks) by Ofgem in benchmarking of the utilities' operating costs. An alternative way to write the cost function (1) is:

$$
\ln C=\ln C(n, d, e, q, t)
$$

where $d=y / n$ is a measure of network density. ${ }^{3}$ Functions (1) and (2) are equivalent. But the interpretation of some coefficients changes, for example, while energy delivered in equation (1) is expressed in absolute terms, in equation (2) it is expressed in relative terms. The advantage of (2) is that it makes easier to measure both economies of scale and economies of density.

\footnotetext{
${ }^{1}$ In technical terms, this means that while translog and quadratic cost functions can be viewed as secondorder approximations to the underlying, and true, cost function, their first derivatives (i.e. elasticities or marginal cost) are only first-order approximations to elasticities or marginal costs.

${ }^{2}$ Customer numbers $(c u)$ and units of energy delivered $(y)$ are the most commonly used outputs in benchmarking of distribution network utilities (Giannakis et al., 2005; and Yu et al. 2009a, 2009b). These output variables are important cost drivers and influence the pricing of distribution services. However, the statistical correlation between these two outputs is very large in the present application (over 97\%). In this case we have four options. The first is to estimate the cost function with both outputs, as in some previous studies. With this strategy not only we are not coping with a significant collinearity problem, but also $c u$ cannot be interpreted as an output because, given that energy delivered is the product of customer number times per capita demand, the derivative of cost with respect to $c u$ captures a substitution effect, i.e. the effect of an increase in the number of customers and simultaneously a reduction in per capita demand. The second option is to drop energy delivered as explanatory variable. This would create an endogeneity problem in the present application as network energy losses depend on total demand and changes in total demand caused by changes in per capita demand - that now belong to the error term- are correlated with energy losses. Hence, if we estimate a cost function by just including customer numbers as output, the parameter of energy losses will be overestimated. The third option, followed in this paper, is to drop customer numbers as output. This does not imply that we ignore $c u$ as it is already included in $y$, and the main driver of change in energy delivered is by far $c u$. On the other hand, as $y$ includes per capita demand, we do not have an endogeneity problem. The fourth option is to add per capita demand as an additional cost driver, but given the small size of our sample and that the coefficient of this variable was always statistically insignificant, we drop this.

${ }^{3}$ Network density is often measured as the ratio of customer numbers to network length. As the correlation between customer numbers and energy delivered is almost $100 \%$, our density measure can be loosely interpreted as the number of customers per network kilometer.
} 
We use the sum of operational and capital expenditures (Totex) as the dependent variable. Improving quality of services involves operating cost (Opex) and capital cost (Capex) for the utilities. Due to the presence of possible trade-offs between Opex and Capex (Giannakis et al. 2005), utilities might adopt different strategies to combine operating and capital inputs to improve service quality. These strategies might be affected by the regulatory incentives. For example, in the UK a firm receives greater benefits from saving Opex than by an equal amount of Capex reduction (Ofgem, 2003a). Hence, in order to examine existence of different strategies in the UK utilities to improve quality, and to ascertain whether the current regulation has distorted the allocation of operating and capital inputs we also consider Capex and Opex as dependent variables. In a previous study (see Jamasb et al., 2010) we added the cost of energy distribution losses to the Totex. Here we use energy losses, $e$, as a cost determinant as we are interested in estimating its effect on total cost of reducing distribution losses.

Both $n$ and $d$ allow us to distinguish between economies of scale and economies of density. The first type is related to system expansion at constant density, e.g. urban fringe expansion. As network density is held constant, this type of expansion requires enlarging the current network to meet extra demand. These economies that involve increases in demand and network can be measured by (partial) elasticity of cost with respect to network length, $n$. The second type involves simultaneously expanding the output and service density, i.e. expansion in the existing serviced area where additional network is not required. These economies can be measured by the (partial) elasticity of cost with respect the network density, $d$. It is expected that the economies in distribution are mostly from increased densities.

Yu et al. (2009b) treated the social cost of customer minutes lost as a cost to be minimized together with private costs. ${ }^{4}$ We treat social and private costs somewhat differently, and include customer minutes lost, $q$, as a determinant of private costs. This allows us to obtain a measure of the private marginal costs of quality improvements. ${ }^{5}$ We multiply the per-customer minutes lost by the number

\footnotetext{
${ }^{4}$ This requires an estimate of customer willingness-to-pay (WTP) for quality improvement. See Yu et al. (2009a) for more details about how WTP can be estimated and problems of obtaining accurate measurement.

${ }^{5}$ Indeed, note that actually customer minutes lost, $q$, is the "inverse" of a real quality measure. If we call this quality measure as $Q$, the marginal cost of quality improvements can be computed as:

$$
M C=\frac{\partial C(\cdot)}{\partial Q}=\frac{\partial C(\cdot)}{\partial q} \cdot \frac{\partial q}{\partial Q}
$$

If the relationship between $q$ and $Q$ can be represented by the linear function $Q=A-q$, where $A$ can be viewed as the maximum quality level, the above marginal cost reduces to:

$$
M C=-\frac{\partial C(\cdot)}{\partial q}
$$

In order to get a positive marginal cost of quality improvements, the derivative of the cost function with respect to $q$ should be negative. It is argued before that this might not be the case as $q$ cost might be negatively and positively correlated.
} 
of customers, in order to scale the variable and include it as a determinant of network company costs.

The coefficient of the time trend is normally interpreted as capturing the cost effect of improvements in technology. In this paper we use a broad definition of technology as the estimated cost function likely reflects both the underlying (physical) technology and the (consequences of the) regulatory regime that conditions utilities' performance. In this sense, the time trend coefficient of the model may also reflect improvements in cost efficiency in response to regulatory incentives.

Unfortunately input price data for operating and capital inputs is not available. By convention, many papers using non-parametric techniques set the price of operating and capital inputs to unity. If we followed the same strategy in a parametric framework (i.e. including invariant input prices), we would not able to distinguish their effect from those of other explanatory variables. In general, we expect that the price effect of operational and capital inputs is captured by the time trend as many industrial prices tend to increase gradually over time, i.e. as with a time trend. Hence, the coefficient of the time trend variable might be capturing the net effect of improvements in technology or cost efficiency and input prices (changes).

Another issue is to control for the effect of differences among utilities in environmental factors, such as the weather, geography, etc. In Jamasb et al. (2010) we show that weather conditions should be included as determinants of distribution costs as they have shown a statistically significant effect on costs, and because ignoring the effect of weather on distribution costs might bias the parameter estimates of other relevant variables. This endogeneity appears because bad weather conditions tend to increase costs but also lead to lower quality.

This case is presented in Figure 2 where we draw two hypothetical cost functions, one for good weather and other bad weather. If the random data generation process behind service quality were completely independent of weather, we would have observations along both cost functions. However, bad weather conditions tend to reduce service quality.

In order to estimate consistently a cost function in the electricity distribution sector, we include weather data as cost determinants. ${ }^{6}$ More specifically, we simply add the weather variables to the cost function as in Jamasb et al. (2010) we could not reject separability and a linear functional form for the weather variables. Our cost function can then be written as. ${ }^{7}$

\footnotetext{
${ }^{6} \mathrm{We}$ also show in Jamasb et al. (2010) how to proceed when weather information is not available in an instrumental variable framework.

7 We do not use weather composites as in Yu et al. (2009b) as we found that statistical weather composites do not have any cost effect even though some of their components have a significant effect on costs. Moreover, the inclusion of weather composites did not allow us to estimate consistently the marginal cost of quality improvements.
} 


$$
\ln C=\ln C(n, d, e, q, t)+g(w)
$$

where $g(w)$ is a linear function and $w$ is a set of weather variables that might affect costs. According to (3), the vertical distance between both good and bad weather cost functions in Figure 2 is now captured by $g(w)$, and consequently the simultaneity biases should now disappear.

Figure 2. Distribution cost, service quality and weather conditions

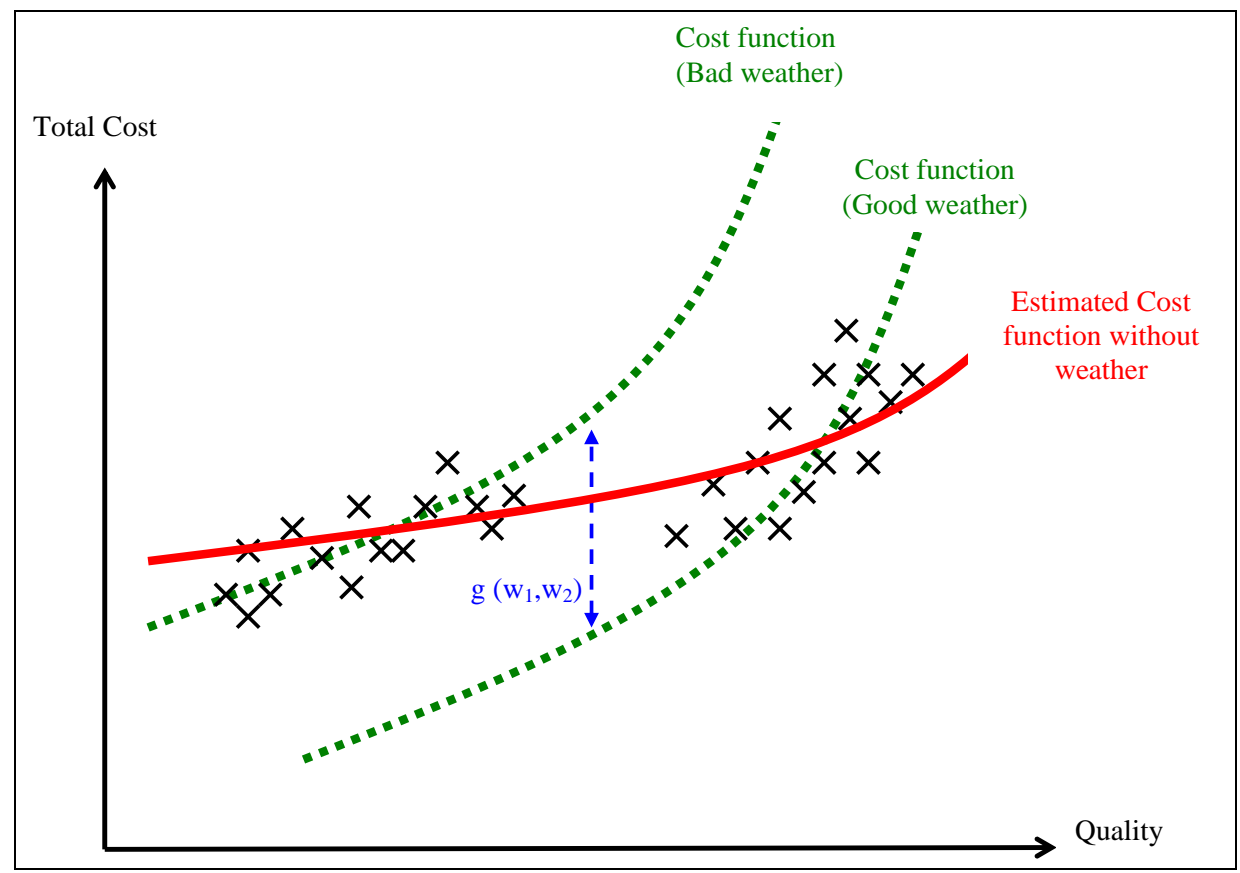

A final issue is that there is a feed-back between service quality and cost, making it difficult to formulate hypotheses with respect to the effect of quality on cost. This is illustrated in Figure 3, where an increase in power interruptions caused by severe weather conditions or equipment decay require corrective costs associated with the steps needed to replace the damaged equipment and to restore power. As a result, we expect a positive (negative) correlation between the number and duration of power interruptions (quality services level) and cost.

At the same time, Yu et al. (2009b) argue that, over time, utilities might adapt their operating and investment practices to prevent power interruptions. As a result, we also expect a positive correlation between quality of service and cost. Hence, quality of service is likely negatively correlated with corrective costs, but positively correlated with preventative costs. 


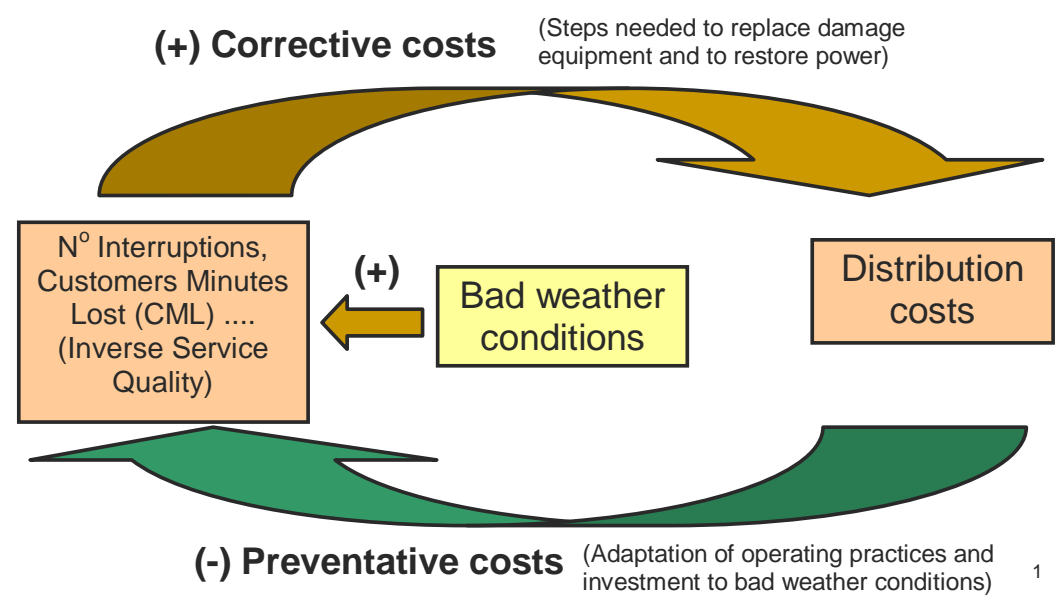

We attempt to distinguish between the types of cost by taking into account that each cost maintains a different relationship with quality of service (number and duration of power interruptions) over time. In other words, some costs are likely correlated with contemporaneous interruptions, while other costs with future or expected interruptions. These (inter)temporal relationships are represented in Figure 4. The figure assumes that corrective costs are logically explained just by contemporaneous power interruptions - i.e. number of minutes lost per customer for planned and unplanned interruptions lasting three minutes or longer, $q=$ CML. ${ }^{8}$ On the other hand, the distribution utilities were incentivized to reduce both the number and duration of interruptions during the period analyzed in the present paper. In 1999, the distribution performance standards were introduced, and the third price review period (2000-2005) introduced an incentive scheme of penalties and rewards focuses on improving rather than maintaining the level of quality. ${ }^{9}$ Given this incentive scheme, it is reasonable to assume that each utility has invested in specific equipment every period to prevent power interruptions in the future. ${ }^{10}$ Obviously, these preventative costs might have also a contemporaneous effect on $q$, resulting in the contemporaneous relationship between total cost and customer minutes lost being indeterminate as the relationship of $q$ with preventative cost is negative, while it is positive with corrective costs.

\footnotetext{
${ }^{8}$ From 2005/06 Ofgem adds 50\% of planned interruptions to planned interruptions as consumer surveys showed that electricity consumers are less affected by the latter.

${ }^{9} \mathrm{It}$ is noteworthy that Ofgem assigned a higher incentive percentage to customer minutes lost rather than number of customers interrupted targets, which shows the relative importance of reducing the length as opposed to the number of interruptions (Yu et al., 2009a).

${ }^{10}$ In this sense, it is important to recall that previous studies have showed that utilities have responded to quality of service incentives (Jamasb and Pollitt, 2007; Tangeras, 2009).
} 
Figure 4. Theoretical framework

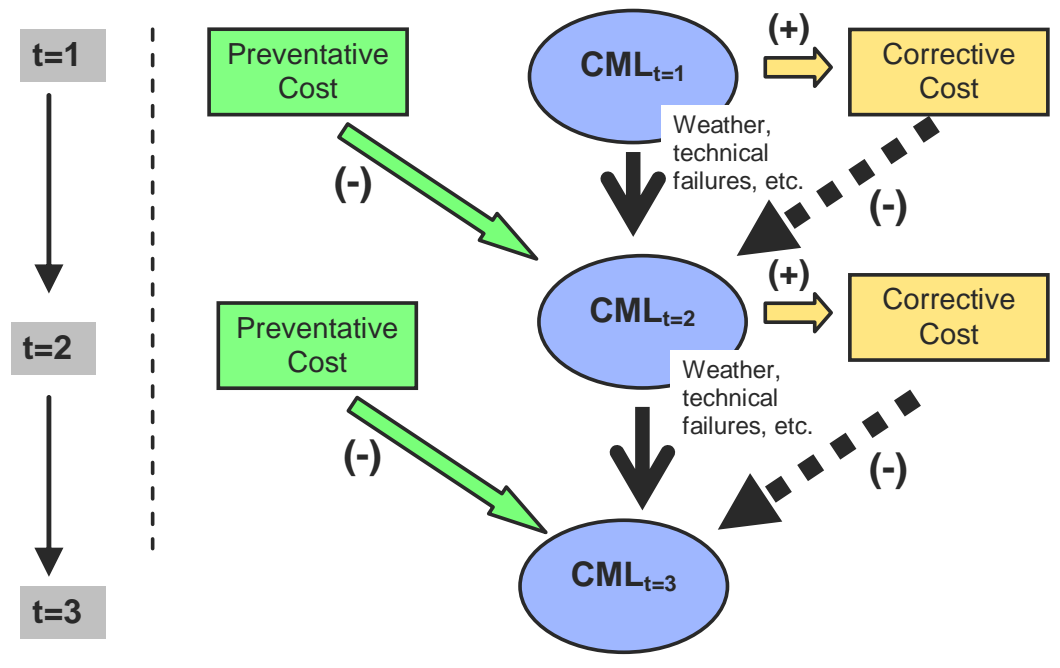

Before describing the implications of this theoretical framework for the specification of the cost function (3), we test whether it is supported by the data. If the above framework is correct: $i)$ the dependence of $q$ on contemporaneous expenditures is likely not statistically significant because not all new equipment to prevent power interruptions are available at the beginning of the period and the negative, although weak, effect on $q$ of preventative costs offsets the positive effect of corrective cost; and ii) customer minutes lost reductions should depend on past rather than contemporaneous expenditures.

In order to test these hypotheses we estimate several models using $q=\mathrm{CML}$ as a dependent variable, and past and contemporaneous values of Totex as explanatory variables. A summary of the results are shown in Table $1 .^{11}$ In all models, Totex lagged one period is always statistically significant, indicating that changes in $q$ depend indeed on past expenditures, as predicted by the framework outlined above. Note, however, that Totex lagged two periods is not statistically significant, even when other cost variables are not included in the model. Also, as expected, the contemporaneous value of Totex does not have a significant effect on current $q$.

Table 1. Relationship between quality service and contemporaneous and past expenditures

\begin{tabular}{lccccc}
\hline & Model 1 & Model 2 & Model 3 & Model 4 & Model 5 \\
\hline Totex & No & No & - & - & - \\
Totex $(-1)$ & Yes & - & Yes & - & Yes \\
Totex(-2) & No & - & - & No & No \\
\hline R-squared & $10.6 \%$ & $7.8 \%$ & $10.4 \%$ & $6.8 \%$ & $10.4 \%$ \\
\hline
\end{tabular}

Notes: Yes (No) indicates that the coefficient is (not) statistically significant at $5 \%$. Dependent variable: $q=$ CML

\footnotetext{
${ }^{11}$ The details of these estimations are available upon request. In order to control for the effect of weather conditions on CML we included weather variables in all models. A fixed-effect (FE) estimator was used as we are interested in temporal changes (i.e. within-firm variations) rather than differences among the utilities. The R-squared statistic is always very low $(<11 \%)$, indicating the existence of other factors not accounted by weather variables and past and contemporaneous values of Totex influencing CML.
} 
The results in Table 1 seem to support the theoretical framework described in Figure 4.12 Next we examine the implications of this theoretical framework on the specification of the cost function (3). In particular, we can hypothesize from Figure 4 that: i) corrective cost depends exclusively on contemporaneous customer minutes lost, q; ii) preventative cost depends on expected customer minutes lost; iii) Totex depends on both contemporaneous and expected customer minutes lost; 13 and iv) while the effect of contemporaneous customer minutes lost on Totex might be both positive or negative, the effect of expected customer minutes lost on Totex should be negative and larger in absolute terms.

In summary, if the above framework holds, the cost function in (3) should be written as:

$$
\ln C=\ln C(n, d, e, q, E q, t)+g(w)
$$

where $E q$ is the expectation in $t$ about customer minutes lost in $t+1$. In this specification, the derivative of cost with respect to $E q$ allows us to measure, once we change its sign, the real marginal cost of quality improvements as this derivative is not "contaminated" by corrective cost effects. ${ }^{14}$ The sign of the derivative of cost with respect to $q$ is unknown as it captures both corrective and preventative effects.

The magnitude of power interruptions in the future is not observed by the utilities (but it is observed by the researchers). For this reason their decisions are likely based on expected values. These expected values are in turn conditioned by the firm-specific targets set by Ofgem to incentivize improvements in service quality. The expected values, however, are not observed by the researchers. Hence, we replace $E q$ by $q$ at $t+1$, that is,

$$
\ln C_{i t}=\ln C\left(n_{i t}, d_{i t}, e_{i t}, q_{i t}, q_{i t+1}, t\right)+g\left(w_{i t}\right)+\varepsilon_{i t}
$$

where subscript $i$ stands for utilities, subscript $t$ stands for time period, and $\varepsilon_{i t}$ is the classical error term. We expect the classical errors-in-variables attenuation bias where the coefficient of the variable measured with error is biased toward zero (Wooldridge, 2002). Therefore, the marginal cost of quality of service improvement estimated using (5) can be viewed as a lower-bound of the real marginal costs.

\footnotetext{
${ }^{12}$ Since preventive and corrective costs might be also applied for reducing energy losses, we have carried out a similar analysis for energy losses as dependent variable. However, none of the coefficients of past and contemporaneous values of Totex were statistically significant.

13 The difference between expected and future customer minutes lost is explained below.

${ }^{14}$ One can argue that some corrective costs might have a preventative effect. In this case, however, its relationship with future customer minutes lost is of the same sign as the pure preventative costs.
} 


\section{Estimation strategy}

In addition to including weather variables as cost determinants, a fixed-effect type estimator is used to control for unobserved heterogeneity among firms that might be correlated with the explanatory variables. The traditional fixed-effect (FE) estimator in the present application may be inappropriate as many crucial determinants of utility costs, such as the energy delivered, the number of customers, or the network length are persistent or rarely variant variables. Plumper and Troeger (2007) pointed out that the FE estimator may be inappropriate because the information between firms is mostly ignored, and the estimates of rarely changing variables are inefficient. In order to address this issue, they propose using the Fixed Effect Vector Decomposition (FEVD) method. They show, through a Monte Carlo analysis, that FEVD has a better performance than OLS, Random Effect Estimator, and the Hausman-Taylor Estimator if time variant and time invariant variables are correlated with fixed effects.

If we use the traditional FE estimator to estimate our cost function, the model to be estimated can be re-written as follow:

$$
\ln C_{i t}=\left[\alpha+\beta x_{i t}+\delta z_{i t}\right]+\eta_{i}+\varepsilon_{i t}
$$

In this equation we have re-label the cost explanatory variables according to their time (within-firm) variability: $x_{i t}$ stands for variables that vary notably over time (such as prices or service quality), and $z_{i t}$ stands for rarely variant variables or time-invariant (e.g. number of customers or network length). The key characteristic of the FE estimator is that it eliminates the concern about any individual fixed error term, $\eta_{i}$, by focusing solely on how much companies vary from their time-means. This is known as the within-firm variation and shown in equation (7):

$$
\ln C_{i t}-\overline{\ln }_{i}=\beta\left(x_{i t}-\bar{x}_{i}\right)+\delta\left(z_{i t}-\bar{z}_{i}\right)+\varepsilon_{i t}-\bar{\varepsilon}_{i}
$$

where

$$
\overline{\ln C}_{i}=\frac{1}{T} \sum_{t=1}^{T} \ln C_{i t} \quad, \quad \bar{x}_{i}=\frac{1}{T} \sum_{t=1}^{T} x_{i t} \quad, \quad \bar{z}_{i}=\frac{1}{T} \sum_{t=1}^{T} z_{i t} \quad, \quad \bar{\varepsilon}_{i}=\frac{1}{T} \sum_{t=1}^{T} \varepsilon_{i t}
$$

By eliminating the unobserved fixed effect, $\eta_{i}$, unbiased estimates of the $x$ variables can be obtained even if the explanatory variables are correlated with the fixed error effect. Since the FE model focuses solely on explaining the within-firm variation, and all of the between-firm information is mostly ignored, it is not possible to obtain reliable estimates on variables that have low within-firm variation using a FE estimator. Moreover, in the extreme case that $z_{i t}=z_{i}$, the FE estimator is not able to distinguish the effect of time-invariant explanatory variables from the fixed effects. The coefficients of persistent variables or rarely variant variables usually become statistically insignificant as their effect are being also captured by the fixed effects. 
However, in our present application rarely variant variables such as the energy delivered, the number of customers, or the network length are crucial cost determinants, and their parameters should be estimated properly. In order to address this issue, Plumper and Troeger (2007) proposed using the FEVD estimator, based on the former FE estimator. The FEVD is a three-stage estimator. In first stage, the fixed effects vector decomposition procedure carries out a standard FE model to obtain estimates of the fixed effects. These can be obtained using the following expression: ${ }^{15}$

$$
\hat{\eta}_{i}=\overline{\ln }_{i}-\hat{\beta} \bar{x}_{i}-\hat{\delta} \bar{z}_{i}
$$

The estimated fixed effects using (8) are not the same as the true unobservable heterogeneity outlined in equation (6) as they also contain the intercept, the eliminated information contained in time-invariant variables, as well as the mean effects of the rarely variant variables. For this reason, Plumper and Troeger (2007) suggest decomposing in a second stage the estimated fixed effects into a part that is observable and a part that is not. The decomposition takes place using both time-invariant and rarely invariant variables to predict the estimated fixed effects obtained from stage one:

$$
\hat{\eta}_{i}=\phi_{0}+\phi \bar{z}_{i}+\omega_{i}
$$

The error term $\omega_{i}$ in equation (9) captures the true unobservable component $\eta_{i}$. In the third stage, the full model (time variant, time invariant, rarely changing variables) is estimated by OLS, including the unexplained part of the decomposed fixed effect vector obtained in the second stage:

$$
\ln C_{i t}=\left[\alpha+\beta x_{i t}+\delta z_{i t}\right]+\zeta \omega_{i}+\varepsilon_{i t}
$$

\section{Data and sample}

We utilize the same dataset as in Yu et al. (2009b) and Jamasb et al. (2010) on 12 distribution networks in the UK for the $1995 / 96$ to $2002 / 03$ period. The crosssectional and time dimension of our panel data set is conditioned by availability of weather data. Two companies were excluded as complete data records of weather in their service areas were not available. In addition, we excluded the 2003/04 data from the analysis, which had been subject to adjustment in order to control for weather related atypical costs. ${ }^{16}$

Two weather stations in the service area of the companies were selected to represent each firm and the averages of their measurements was taken (if two

\footnotetext{
${ }^{15}$ Here we assume that all $\mathrm{z}$ variables have a, albeit low, within-firm variation. Otherwise, the fixed effects should be obtained using only the average values of the high-within-firm-variation variables.

${ }^{16}$ It should be noted that we use data on service quality for the years 2003/2004 in order to compute the expected customer minutes in the future.
} 
weather stations were not available, one weather station was used). All yearly weather data is used to maximize the use of the information available for each company. We use four weather variables, viz. minimum air temperature (mate), the number of days when minimum concrete temperatures were below zero degrees (dcte), the number of days with heavy hail (dhail), and the number of days with heard thunder (dthu). In Jamasb et al. (2010) we have shown that these were sufficient to control for most of the effect of weather conditions on costs.

Table 2 reports the summary statistics of the data used. The monetary and physical data for the inputs and outputs are based on publications and information from Ofgem. The data on service quality is mainly based on information from Ofgem's annual Electricity Distribution Quality of Service Report. The weather data were obtained from the UK Meteorological office for most observation stations. All monetary variables are expressed in 2003 real terms. Temperatures are expressed in degrees Celsius and the remaining variables are expressed in number of days per year.

Table 2: Descriptive Statistics (96 Observations)

\begin{tabular}{|c|c|c|c|c|c|c|}
\hline Description & Variable & Unit & Mean & $\begin{array}{l}\text { Std. } \\
\text { dev. }\end{array}$ & Min & Max \\
\hline Total expenditures & Totex & Million $€$ & 177.38 & 62.80 & 74.86 & 373.88 \\
\hline Capital expenditures & Capex & Million $€$ & 85.92 & 33.00 & 36.00 & 203.94 \\
\hline $\begin{array}{l}\text { Operational } \\
\text { expenditures }\end{array}$ & Opex & Million $€$ & 91.46 & 43.52 & 30.64 & 267.02 \\
\hline Network length & $n$ & $\begin{array}{l}\text { Thousand } \\
\text { Km }\end{array}$ & 55.84 & 15.27 & 32.002 & 92.121 \\
\hline $\begin{array}{l}\text { Network density= } \\
\text { (Energy delivered) / } \\
\text { Network length) }\end{array}$ & $d$ & GWh / Km & 0.37 & 0.07 & 0.15 & 0.48 \\
\hline $\begin{array}{l}\text { Energy Distribution } \\
\text { Losses }\end{array}$ & $e$ & $\begin{array}{l}\text { Thousand } \\
\text { GWh }\end{array}$ & 1.53 & 0.58 & 0.36 & 2.61 \\
\hline $\begin{array}{l}\mathrm{CML}=(\text { Customer } \\
\text { minutes lost) } \mathrm{x} \text { ( } \mathrm{n}^{\circ} \text { of } \\
\text { customers) }\end{array}$ & $q$ & $\begin{array}{l}\text { Million } \\
\text { Minutes }\end{array}$ & 163.75 & 76.58 & 60.67 & 670.58 \\
\hline $\begin{array}{l}\text { Minimum air } \\
\text { temperature }\end{array}$ & mate & Degrees C & 1.06 & 1.57 & -1.9 & 5.7 \\
\hline Hail & dhail & Days & 2.25 & 2.66 & 0 & 14 \\
\hline Thunder & $d t h u$ & Days & 10.57 & 5.93 & 2 & 27.4 \\
\hline Concrete temperature & dcte & Days & 57.76 & 22.97 & 14.6 & 107.5 \\
\hline Willingness-to-pay & $W T P$ & $£ / \mathrm{min}$ & 1.93 & 0.61 & 0.87 & 3.82 \\
\hline
\end{tabular}

Description of the Weather Variables: mate=Minimum air temperature (lowest monthly average). dcte=Number of days when minimum concrete temperature was below zero degrees $\mathrm{C}$. dhail=Number of days when hail fell (00-24 GMT) ie. solid precipitation with a diameter $5 \mathrm{~mm}$ or more. $d$ thu=Number of days when thunder was heard. 


\section{Empirical results}

According to Section 2 we estimate a translog specification of the cost function (5). This function can be interpreted as second-order approximation to the companies' underlying cost function. All explanatory variables were divided by the sample geometric mean, so the first order parameters can be interpreted as elasticities at the sample geometric means. Table 3 shows the parameter estimates. Using the Breusch-Pagan LM chi-squared test we reject the null hypothesis of no heteroskedasticity at the 5\% percent level of significance for all specifications of the cost function. Although accounting for heteroskedasticity does not produce significant changes in inference, we report the White heteroskedasticity-consistent t-ratios.

Table 3 shows the estimated coefficients using OLS, FE and FEVD. All elasticities in the OLS model have their expected signs at the sample geometric mean: the estimated first-order coefficients of network length $\left(n_{i t}\right)$ and network density $\left(d_{i t}\right)$ are positive and statistically significant, and the coefficient of energy losses $\left(e_{i t}\right)$ and lead of the customer minutes lost $\left(q_{i t+1}\right)$ are negative, suggesting a positive marginal cost of quality improvements that we discuss later. As expected, the effect of contemporaneous customer minutes lost $\left(q_{i t}\right)$ on Totex is not statistically significant. This suggests that contemporaneous power interruptions are positively correlated with corrective cost, but negatively correlated with costs caused by the acquisition of new equipment to prevent power interruptions (in the future). Overall, these results seem to support the theoretical framework described in Figure 4.

Table 3. Translog cost function parameter estimates. Dependent variable: $\ln$ Totex

\begin{tabular}{lrccccc}
\hline & \multicolumn{2}{c}{ OLS } & \multicolumn{2}{c}{ FE } & \multicolumn{2}{c}{ FEVD } \\
\cline { 2 - 7 } Variable & parameter & robust-t & parameter & robust-t & parameter & robust-t \\
\hline $\ln n_{i t}$ & 1.3137 & 8.7892 & 0.6714 & 0.4663 & 1.2086 & 7.7896 \\
$\ln d_{i t}$ & 0.7845 & 4.2300 & -0.1387 & -0.2491 & 0.6808 & 3.7828 \\
$\ln e_{i t}$ & -0.2969 & -2.8668 & -0.0737 & -0.3475 & -0.2568 & -2.4902 \\
$\ln q_{i t}$ & -0.0341 & -0.4747 & 0.0010 & 0.0126 & 0.0093 & 0.1257 \\
$\ln q_{i t+1}$ & -0.2480 & -3.0383 & -0.1919 & -2.2565 & -0.2160 & -2.7604 \\
$1 / 2\left(\ln n_{i t}\right)^{\wedge}$ & 1.7211 & 1.0945 & 5.5295 & 1.4673 & 1.6463 & 1.1039 \\
$1 / 2\left(\ln d_{i t}\right)^{\wedge}$ & -0.4202 & -0.3202 & 1.4715 & 1.0862 & -0.5422 & -0.4197 \\
$1 / 2\left(\ln e_{i t}\right)^{\wedge}$ & -0.6036 & -1.2321 & -0.1490 & -0.2008 & -0.3739 & -0.8167 \\
$1 / 2\left(\ln q_{i t}\right)^{\wedge}$ & 0.6710 & 1.9141 & 0.3854 & 0.9031 & 0.4614 & 1.3446 \\
$1 / 2\left(\ln q_{i t+1}\right)^{\wedge}$ & 0.3961 & 1.1266 & 0.4137 & 1.1734 & 0.4154 & 1.2001 \\
$\ln n_{i t} \cdot \ln d_{i t}$ & 0.6638 & 0.5203 & 0.2362 & 0.1496 & 0.9398 & 0.7790 \\
$\ln n_{i t} \cdot \ln e_{i t}$ & -0.2116 & -0.2246 & -0.7062 & -0.6110 & -0.3896 & -0.4481 \\
$\ln n_{i t} \cdot \ln q_{i t}$ & -0.2797 & -0.5321 & 0.0875 & 0.1586 & -0.0816 & -0.1545 \\
$\ln n_{i t} \cdot \ln q_{i t+1}$ & 0.1543 & 0.2289 & -0.0574 & -0.0841 & -0.0805 & -0.1183 \\
$\ln d_{i t} \cdot \ln e_{i t}$ & 0.5495 & 0.7925 & -0.0393 & -0.0561 & 0.3875 & 0.6240 \\
$\ln d_{i t} \cdot \ln q_{i t}$ & 0.7856 & 1.8963 & 0.8472 & 1.9838 & 0.8426 & 2.0387 \\
$\ln d_{i t} \cdot \ln q_{i t+1}$ & -0.7298 & -1.5345 & -0.0947 & -0.1783 & -0.6232 & -1.3349 \\
$\ln e_{i t} \cdot \ln q_{i t}$ & -0.4021 & -1.8871 & -0.3348 & -1.4702 & -0.4003 & -1.8977 \\
$\ln e_{i t} \cdot \ln q_{i t+1}$ & 0.2077 & 0.6096 & 0.2728 & 0.7830 & 0.1867 & 0.5505 \\
\hline
\end{tabular}




\begin{tabular}{|c|c|c|c|c|c|c|}
\hline $\ln q_{i t} \cdot \ln q_{i t+1}$ & -0.8958 & -2.6992 & -0.9303 & -2.4735 & -0.8400 & -2.6355 \\
\hline $\mathrm{t}$ & -0.0875 & -10.2738 & -0.0895 & -6.1815 & -0.0873 & -10.243 \\
\hline mate $_{i t}$ & 0.0827 & 3.6185 & 0.1170 & 5.3073 & 0.0877 & 4.0957 \\
\hline dcte $_{i t}$ & 0.0318 & 3.9541 & 0.0216 & 1.7615 & 0.0336 & 4.2502 \\
\hline dhail $_{i t}$ & 0.0047 & 1.1771 & 0.0072 & 1.2156 & 0.0087 & 1.6125 \\
\hline$d t h u_{i t}$ & 0.0060 & 3.8060 & 0.0051 & 2.4659 & 0.0063 & 4.0806 \\
\hline Intercept & 5.5325 & 147.241 & - & - & 5.5462 & 139.267 \\
\hline Fixed Effects & - & - & - & - & 0.8983 & 1.7664 \\
\hline R-squared & \multicolumn{2}{|c|}{0.8332} & \multicolumn{2}{|c|}{0.7192} & \multicolumn{2}{|c|}{0.8389} \\
\hline
\end{tabular}

The FE estimator allows us to control for unobserved heterogeneity among firms that may be correlated with the explanatory variables. The use of the FE estimator in the present application is clearly inappropriate as the first-order coefficients of network length $\left(n_{i t}\right)$, network density $\left(d_{i t}\right)$ and energy losses $\left(e_{i t}\right)$ are not statistically significant. This is caused by the fact that the within variation of these variables (i.e. the variation over time with respect to the respective firm average) is very low (Table 4). Indeed, the within firm variation of network length, network density and energy losses is much lower than the variation among firms, i.e. the between variation. As many relevant cost determinants have large between-towithin variations, a large amount of observable information will be discarded when using the FE model. Depending on the correlation between the unobservable heterogeneity and any cost determinant, estimation using FEVD might be the preferred estimation strategy. ${ }^{17}$

Table 4. Between and within standard deviations

\begin{tabular}{lccc}
\hline Variable & Between & Within & Between-to-within ratio \\
\hline $\ln n_{i t}$ & 0.27620 & 0.02693 & 10.25509 \\
$\ln d_{i t}$ & 0.24396 & 0.06310 & 3.86661 \\
$\ln e_{i t}$ & 0.42712 & 0.14131 & 3.02259 \\
$\ln q_{i t}$ & 0.28697 & 0.25465 & 1.12693 \\
$\ln q_{i t+1}$ & 0.32038 & 0.24386 & 1.31382 \\
\hline
\end{tabular}

Since the between-to-within variation of network length is larger than 10, it is larger than 3 for network density and energy losses, FEVD is likely a better estimator than FE. For this reason, we estimate a FEVD model using these three variables, their squares and their interactions as regressors in the second stage. The final estimates are obtained by estimating (5) including, as an additional regressor, the unexplained part of the decomposed fixed effect vector obtained in the second stage. The FEVD results are shown in the last two columns in Table 3.

\footnotetext{
17 Plumper and Troeger (2007) advocate using the ratio between-to-within variation as a way of distinguishing whether a particular variable can be better estimated using FEVD. Using Monte Carlo simulations, they show that this ratio, however, depends on how well the particular variable in question is correlated with the unobservable heterogeneity. For example, when the correlation is 0.5 the between-towithin ratio must exceed 2.8 for the FEVD to be the superior estimator. When the correlation drops to 0.3 the between-to-within the person ratio only needs to be 1.7 .
} 
The last two columns in Table 3 show that all elasticities of Totex with respect network length, network density, energy losses and the lead of the customer minutes have again their expected signs at the sample geometric mean, i.e. the coefficients of $n_{i t}$ and $d_{i t}$ are positive, the coefficients of $e_{i t}$ and $q_{i t+1}$ are negative, and the effect of $q_{i t}$ on Totex is not statistically significant. The coefficient of the residual fixed effects is close to unity. We use this result as evidence that the FEVD model is well specified. Although the magnitudes of the first-order FEVD coefficients are somewhat less than the OLS counterparts, they are quite similar, indicating that most of the fixed effects are explained by rarely variant variables (i.e. network length, network density and energy losses) ${ }^{18}$, and that the use of the FE estimator is not appropriate in the present application.

On the other hand, the coefficient of the time trend is negative and statistically significant, indicating either a general increase in cost efficiency or the existence of technical progress in the sector. This improvement in performance may be caused by the current regulatory regime in the UK as each firm is incentivized to save both operating cost and capital cost. It is worth mentioning that when Capex is used as the dependent variable (see Appendix) the improvement in performance is lower (about 3\%) than when we use Totex (about 8\%). This implies that the rate of improvement in Opex is much larger than in Capex.This is a reasonable result as in the UK a firm receives greater benefits from saving Opex than Capex (Ofgem, 2003) over the sample period ${ }^{19}$. Hence, this result seems to support the former notion that the current regulation framework in the UK has distorted significantly the allocation of operating and capital inputs. Regarding the weather factors, most weather coefficients are statistically significant (even when we control for unobserved time-invariant variables) indicating that weather conditions matter and that they should be included as cost determinants. ${ }^{20}$

Network length $\left(n_{i t}\right)$ and network density $\left(d_{i t}\right)$ allow us to measure respectively economies of scale and economies of density. Economies of scale are related to system expansion at constant density and hence it can be measured by the partial elasticity of cost with respect to network length. The first-order coefficient of network length is 1.2086. That is, the technology exhibits decreasing returns to scale at the sample mean when expansion requires enlarging the current network to meet extra demand. Some previous studies have found diseconomies of scale in the electricity distribution (see e.g. Yatchev, 2000; Cronin and Motluk, 2007). On the other hand, economies of density involve simultaneously output expansion and service densification, i.e. expansion in the existing service areas where additional network is not required. The first-order coefficient of network density is 0.6808 , indicating that economies of density are higher than economies of scale

\footnotetext{
${ }^{18}$ The R-square statistic of the second stage is about $97 \%$.

19 This has been altered for the price control period beginning in April 2010 (see Ofgem, 2009).

20 As weather is a complex phenomenon and its overall effect on cost is unknown, we take an agnostic position and do not make specific assumptions about the probable (partial) effect of each weather variable on distribution costs. Alternatively, given the large correlation among some of the weather variables, a particular weather variable may be capturing not only their own effect but also the effect of other (correlated) variables that might have a non expected sign or magnitude. In this sense, what matters is the overall effect and not the effect of each particular weather variable.
} 
(Guldmann, 1985; Filippini, 1998), and that increasing returns arise from increased densities. That is, given network infrastructure, electricity distribution networks have natural monopoly characteristics. ${ }^{21}$

Figure 5 depicts the elasticity of total cost with respect to network length estimated for each observation, sorted by network length. ${ }^{22}$ Using the parameter estimates of the model with Capex as dependent variable (see Appendix) we also compute the elasticity of capital cost with respect to network length. In order to be consistent with the previous two equations, the elasticity of operational cost is then obtained using the equation (11):

$$
\text { elas }_{2}=\frac{\text { elas }-e^{e l a s_{1}} \cdot s_{1}}{s_{2}}
$$

where elas is the elasticity of total cost, elas 1 is the elasticity of capital cost, elas 2 is the elasticity of operational cost, and $s_{1}$ and $s_{2}$ are respectively the share of Capex and Opex on total cost. ${ }^{23}$ Figure 5 shows that firstly, Totex elasticity of scale increases with size (in terms of network length) where the smallest companies exhibit increasing returns to scale, and medium to large companies exhibit decreasing returns to scale. Secondly, both Capex scale elasticity and Opex scale elasticity are positive, indicating that both types of cost increase (i.e. they are complementary) when additional network is required to meet extra demand. Finally, while Opex scale elasticity is lower than unity, Capex scale elasticity is increasingly higher than one, indicating that the "decreasing nature" of Totex scale elasticity is caused by decreasing returns to scale in Capex.

Using the parameter estimates of the model with Totex and Capex as dependent variables and the equation (11) we depict in Figure 6 the three types of density elasticities, sorted by network density. ${ }^{24}$ The negative values and the abrupt changes on the left in both Capex and Opex density elasticities should be viewed with caution as they correspond to some observations exhibiting a network density far away from the sample mean. ${ }^{25}$ With this caution in mind, we can see

\footnotetext{
${ }^{21}$ Also Salvanes and Tjøtta (1998) find evidence of natural monopoly characteristics in the Norwegian electricity distribution networks.

${ }^{22}$ We note again that our elasticity function (i.e. the first derivative of our cost function) just provides a first-order approximation to the underlying elasticity at the sample mean, and hence the estimated elasticities tend to lose reliability when we move away from the sample mean.

${ }^{23}$ In order to smooth the series we control for changes in other variables and evaluate the other cost determinants at the sample mean. Hence, the decomposition in Figure 5 (and following figures) allows us to analyze changes in elasticities or marginal costs of a "representative" utility that increases or reduces its size (or its density or quality level in the following figures). Similar results are obtained, however, if we do not control for changes in other variables.

${ }^{24}$ Again we evaluate the other cost determinants at the sample mean in order to compute these elasticities. 25 For most functional forms (e.g., the translog function) there is a fundamental trade-off between flexibility and theoretical consistency. For instance, maintaining global monotonicity (e.g. positive elasticities and marginal costs) is impossible without losing second order flexibility. For example, Barnett et al. (1996) show that the monotonicity requirement is by no means automatically satisfied for most functional forms, and that violations are frequent.
} 
that, in contrast to Figure 5, Opex density elasticity is normally negative, suggesting that Opex decreases when network density increases.

Figure 5. Elasticities of scale

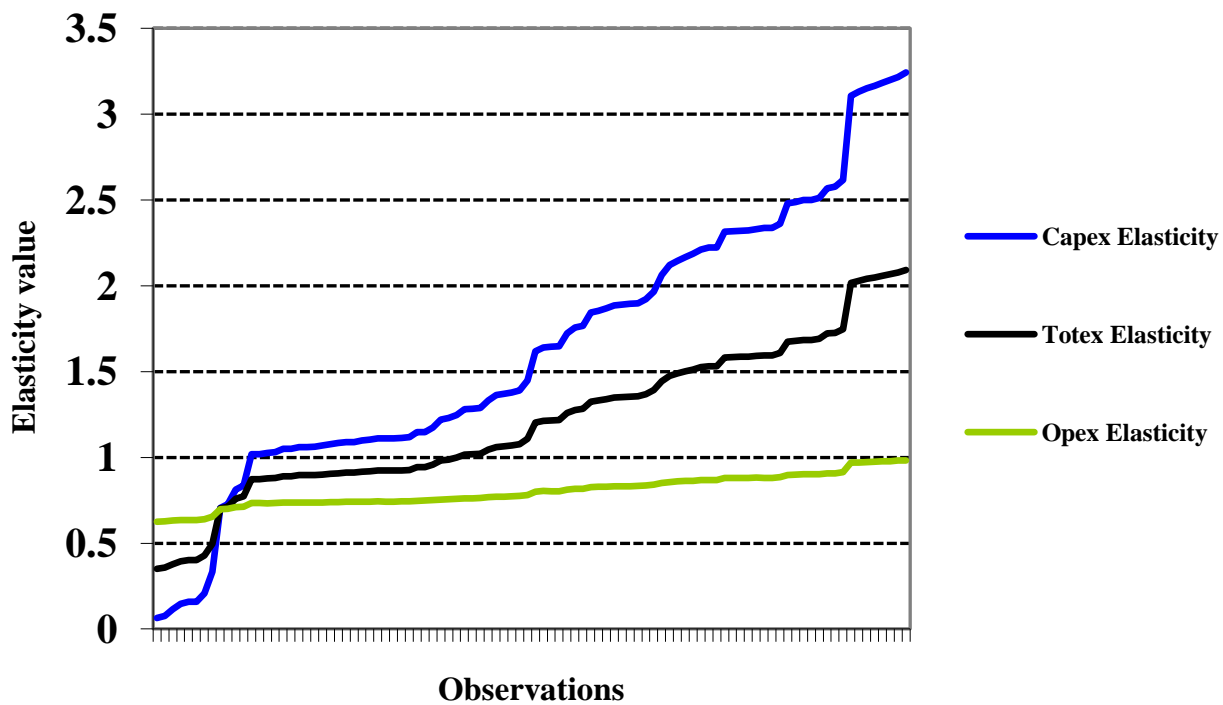

In addition, since Capex density elasticity is positive, as seen from Figure 6, and in contrast to Figure 5 again, we can conclude that utilities tend to substitute Capex for Opex as network density increases. This means that low and high network density utilities adopt different combinations of operating and capital inputs. The less operating intensive strategy followed by high network density utilities may be explained by different consumer mix (e.g. household vs. industrial users) or differences in service areas (e.g. urban vs. rural). Huang et al. (2009) also found two different cost structures for low and high network density utilities in their study of electricity distribution firms in Taiwan.

Figure 6. Density elasticities

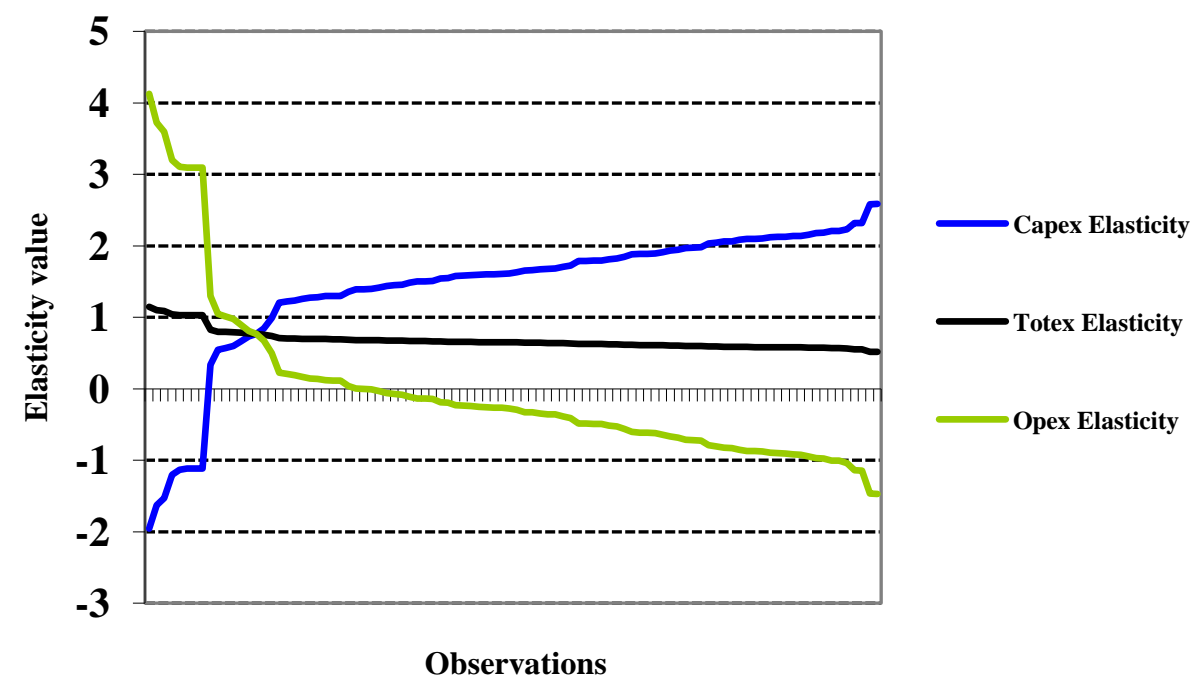


We aim to estimate econometrically marginal costs of improving quality services of the utilities in order to shed light on the effectiveness of the current regulatory incentives in the UK to improve quality. Once we estimate the translog cost model, a marginal cost value can be obtained for each firm using the following equation:

$$
M C=-E L \cdot \frac{C}{z}
$$

where $E L$ is the elasticity of cost with respect to $z$, and $z$ stands for either network energy losses or total customer minutes lost.

Using the parameter estimates of the FEVD model in Table 3 we compute the marginal costs of reducing energy losses for each firm as shown in Figure 7 . The last two columns in Table 3 show that the first-order coefficient of energy losses (in logs) is negative and statistically different from zero. This suggests that, on average, the marginal cost of reducing electricity losses is positive. The average marginal cost in our sample is about 2.8 pence per $\mathrm{kWh}$. Note that the magnitude is smaller than the 4.8 pence per $\mathrm{kWh}$ set by the regulator to reward (penalize) loss reductions (increases) in the fourth control period (Joskow, 2006 and Yu et al. 2009a). Hence, we can conclude that the scheme established by regulators to incentive utilities to reduce their levels of electricity distribution losses is sufficient to improve performance. However, we might expect that this improvement will not be homogeneous as many observations in Figure 7 have higher marginal costs than 4.8 pence per $\mathrm{kWh}$, and hence they are not sufficiently incentivized to reduce their electrical losses, though we note that the value of loss reduction should relate to the wholesale cost of power and any un-priced associated environmental externality.

Figure 7. Marginal cost of reducing electricity distribution losses

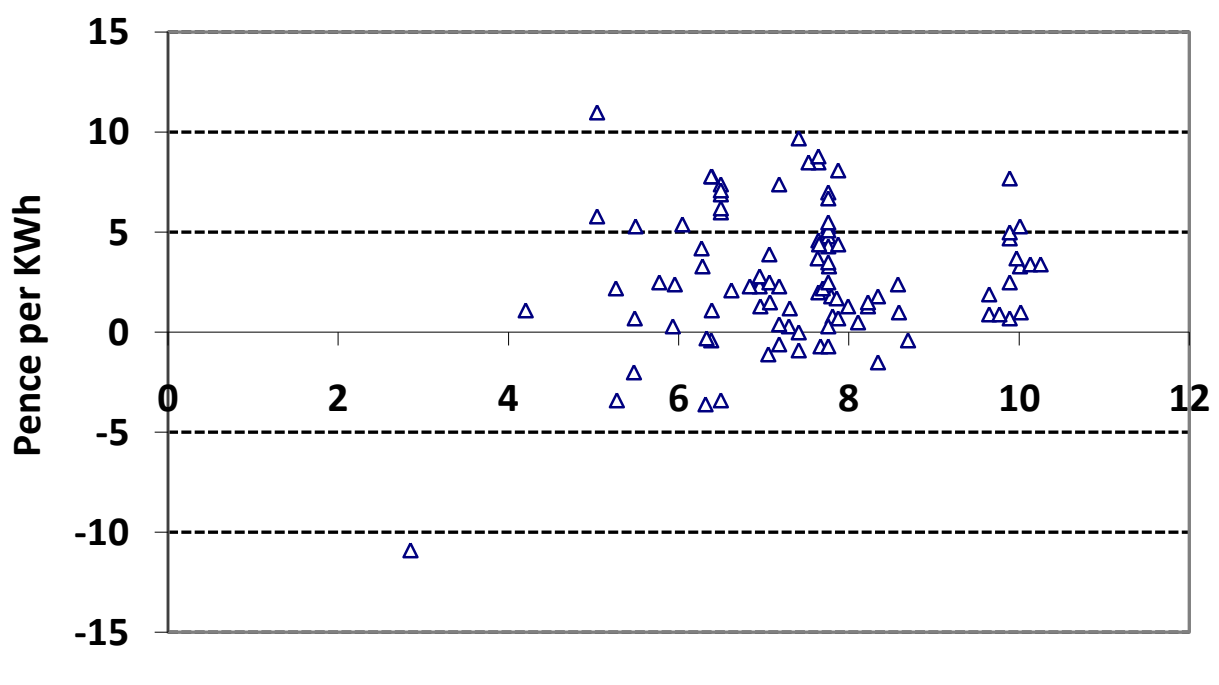

\% Distribution Losses 
Using the parameter estimates of the model with Totex and Capex as dependent variables and equation (12) we compute the total, capital and operational marginal costs of reducing energy losses for each firm. The computed values are shown in Figure 8. With the same caution regarding the values on the left, we can identify three different regions in Figure 8, according to the relative weight of Capex and Opex in total marginal cost. These regions loosely correspond to small, medium, and large utilities, and suggest different strategies to reduce energy losses. Indeed, in the first region, i.e. small utilities, reducing losses mainly implies operational expenses because Opex marginal cost is positive, while Capex marginal cost is negative. In the second region, i.e. medium utilities, both Capex and Opex marginal costs are similar in magnitude and positive indicating that improving quality service implies an investment in both capital and operational inputs. For large utilities, i.e. the third region, Capex marginal cost is considerably larger than Opex marginal cost, indicating that for low quality utilities (in absolute terms) reducing losses mostly requires capital investments. Overall, these results suggest the presence of different strategies among the UK distribution utilities to improve service quality.

Figure 8. Decomposing marginal cost of reducing electricity distribution losses

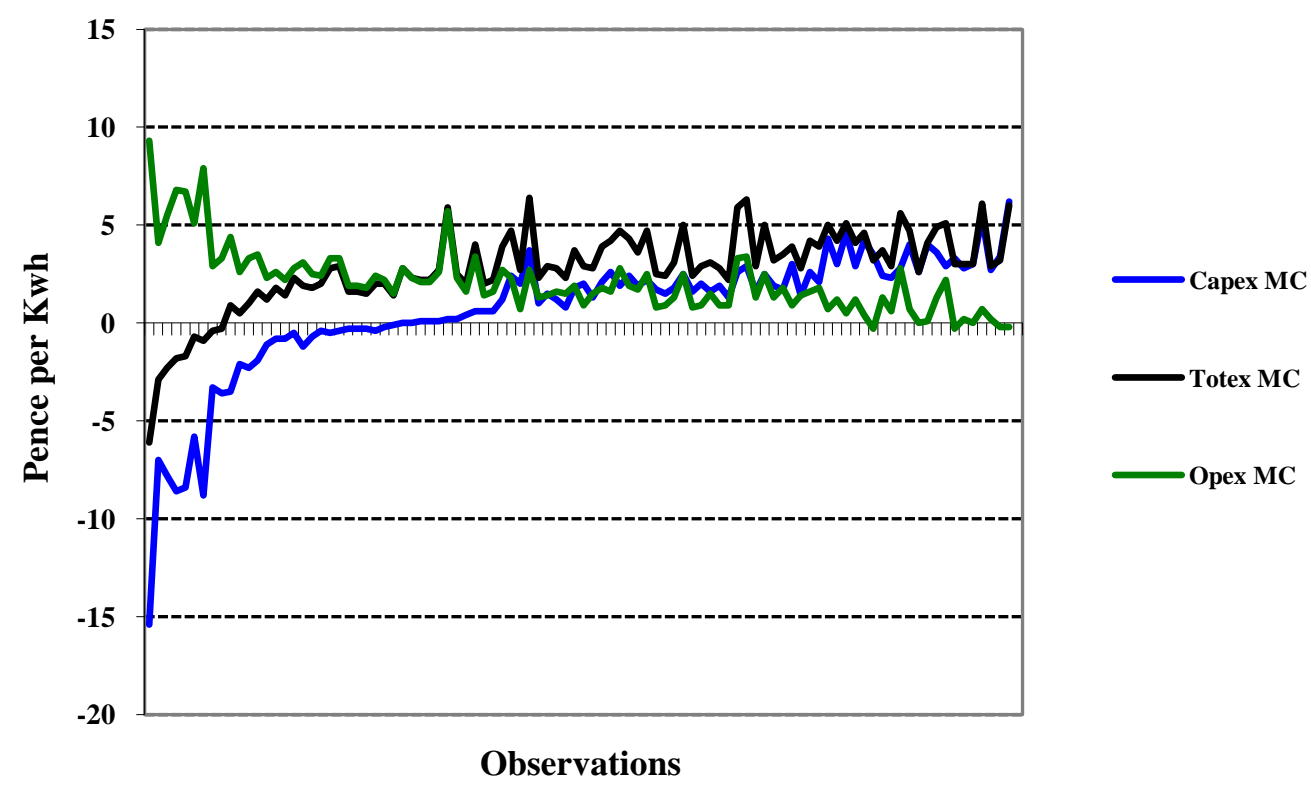

The blue dots in Figure 9 represent the estimated marginal costs of reducing the customer minutes lost by one minute. These values were obtained using the parameter estimates of the FEVD model in Table 3 and equation (12). The marginal costs were obtained by computing the elasticity of cost with respect to the lead customer minutes lost, $q_{t+1}$, as this elasticity is not "contaminated" by corrective costs and, hence, it tends to capture preventative marginal costs. The green dots simulate the marginal cost in case other cost determinants are evaluated at the sample mean. Two comments are in order. First, the green dots suggest a decreasing relationship between marginal cost and customer minutes lost. This implies that, as shown in Figure 1, higher quality level is associated with 
higher marginal cost of quality improvement (see Yu et al., 2009a). Second, the large dispersion of the blue dots around the green dots indicates that the marginal cost of improving quality varies considerably across utilities due to their different configuration (i.e. network length, network density, weather conditions, etc.). However, given their own configuration, all of them have similar downward marginal cost curves to that represented in Figure 9 for the "representative" utility.

Figure 9. Marginal cost of reducing customer minutes lost

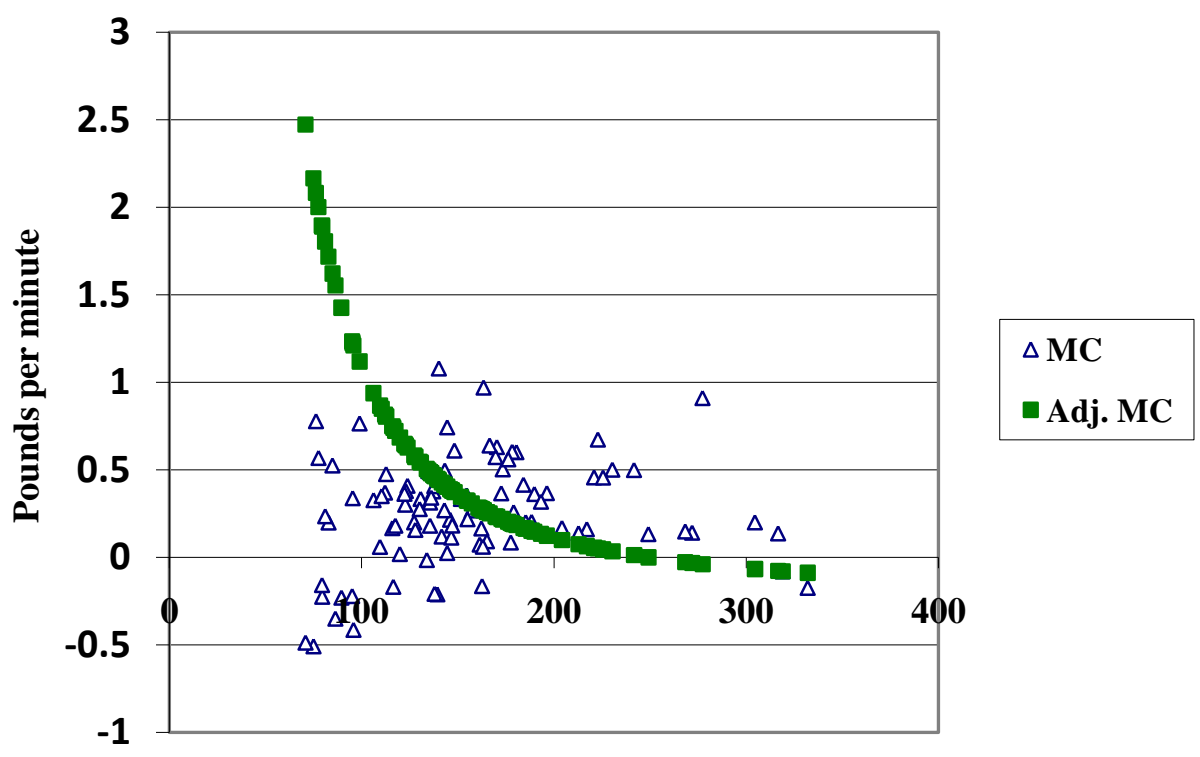

Total Customer Minute Lost

The last two columns in Table 3 show that the first-order coefficient of $\ln q_{t+1}$ is negative and statistically different from zero. This suggests that, on average, the marginal cost of reducing customer minutes lost is positive and statistically significant. In particular, the average marginal cost in our sample is about 25.6 pence per minute lost. Multiplying this by the number of customers we get the marginal cost of avoiding one minute across all customers. This marginal cost of one minute per customer is equal to 0.56 million pounds for the average utility in our sample (6.72 million pounds for the 12 analyzed utilities). Hence, the marginal costs estimated here are considerably larger than the incentive rates established by the UK regulator for each utility in the most recent price review to reduce customer minute lost (see, Joskow, 2006, p.56). Indeed, using the period 2004/5 as a reference, the average incentive for one minute per customer is 0.18 million pounds, i.e. a third of the estimated marginal cost per customer. As $\mathrm{Yu}$ et al. (2009a) already found, we can conclude as well that the UK incentives are not sufficiently strong to incentivise improvements in service quality. In particular, $\mathrm{Yu}$ et al. (2009a) found that the social cost of outages (measured by multiplying business and domestic willingness-to-pay by total customer minutes lost) was considerably higher than the utilities' current incentive/penalty.

On the other hand, as pointed out by Joskow (2006), it is not clear where the values for the incentive rates established by the UK regulator for each utility 
originate from. However, it is expected that they are correlated with utilities' marginal cost. Indeed, using the incentive rates for the period 2004/5, the coefficient of correlation with our marginal costs is quite high, about $46 \%$. This coefficient rises until 55\% if we compare the incentive rates with the marginal cost of avoiding one minute per customer. This suggests that, although the estimated cost function in Table 3 only provides at the sample mean a first-order approximation to the underlying marginal costs, the estimated differences among utilities seem to be reliable. Conversely, since marginal costs of improving quality vary across utilities as different (higher) quality levels are associated with different (higher) marginal costs and there are large differences among utilities in size and network characteristics, our results suggest tailoring the incentives for each utility. The high correlation between incentive rates and estimated marginal costs seems to indicate that the regulator has taken, to some extent, into account the differences in marginal costs to design the incentive schemes in the UK.

Using the parameter estimates of the model with Totex and Capex as dependent variables and equation (12) we have computed the total, capital and operating marginal costs of reducing customer minute lost for each observation. The computed values are shown in Figure 10. The left side of Figure 10 corresponds to high quality utilities, and movements to the right represent deteriorations in quality. As in Figure 6, the different weight of Capex and Opex in total marginal cost, and its evolution, suggests presence of different strategies to improve consumer service quality. Indeed, for low quality utilities, reducing customer minutes lost mostly implies increasing operational inputs. In contrast, when service quality is already high, reducing customer minutes lost even more mostly implies investing in capital inputs. This investment might imply, for instance, acquiring sophisticated equipment or undergrounding activities which are likely quite expensive. This also explains why the marginal cost of quality improvement for high quality utilities is larger than for low quality companies.

Figure 10. Decomposing marginal cost of avoiding power interruptions

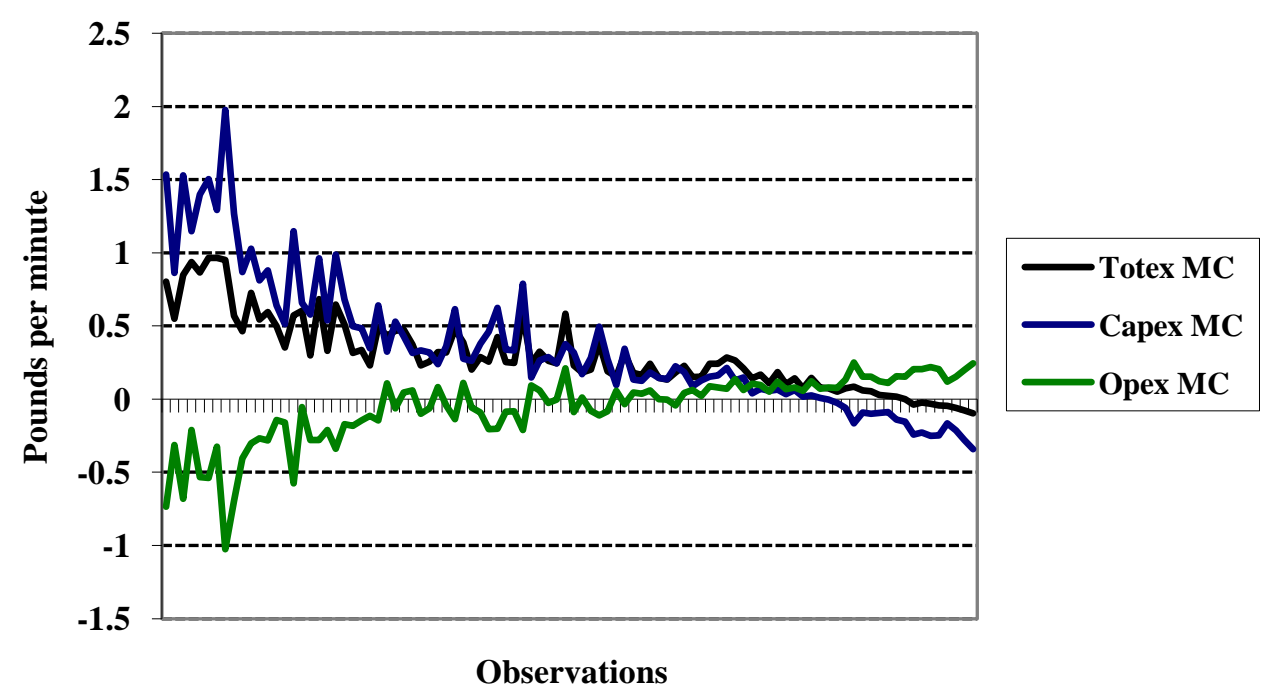


Finally, as illustrated in Figure 11, the estimated marginal costs allow us to know how far the utilities are from their optimal quality level and to compute welfare losses due to sub-optimal quality levels. This requires an estimate of customer willingness-to-pay (WTP) for quality improvement. To this end, we use the WTP data used by Yu et al. (2009a). This data covers domestic and business customers and was obtained from the Ofgem-Accent's customer survey of WTP for quality of service in 2004 (Ofgem, 2004). ${ }^{26}$ For the sample analyzed in the present paper, the WTP for avoidance of a one minute power interruption is on average about 1.92 pounds. However, the preliminary results from the last survey carried out in 2008 seem to suggest that the former WTP is overestimated (see Accent, 2008, p.103). For this reason, we also simulate the optimal quality levels assuming that underlying WTP might be 75 and 50\% of the former WTP. ${ }^{27}$

Figure 11. Optimal vs. actual quality levels and welfare gains

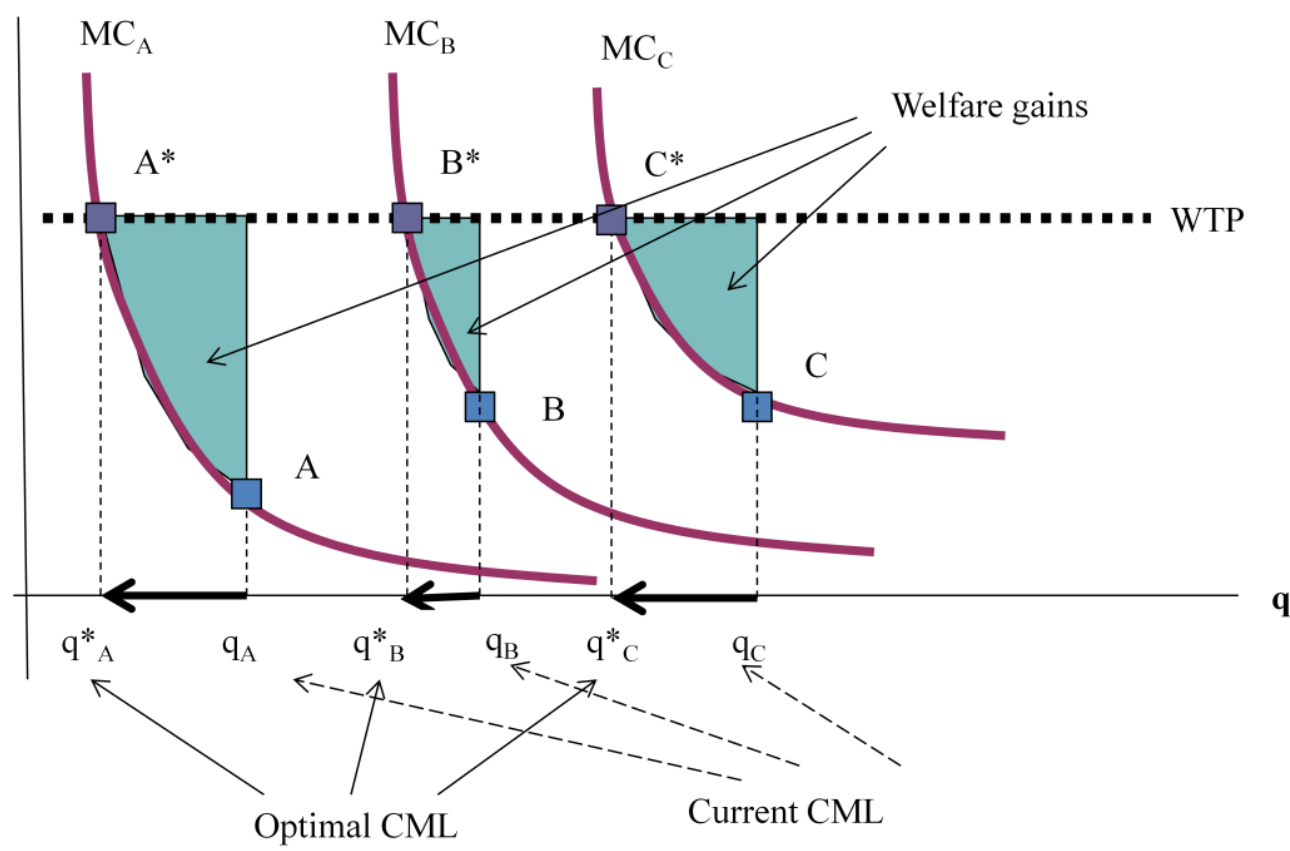

The simulation results are presented in Table 5. Any of the WTP values shown in Table 5 when compared to the estimated marginal costs suggest that actual service quality is on average far from the optimal levels. The results are per company. In particular, while actual customer minutes lost is about 161 million on average, the optimal customer minute lost is $29-45 \%$ less than the actual levels. Moving from

\footnotetext{
${ }^{26}$ See Yu et al. (2009a) for more details about how WTP can be estimated and problems of obtaining accurate measurement.

27 These adjustments can also be justified as our marginal cost of quality improvement might be underestimated due to the variable-in-error problem mentioned in the model specification section.
} 
actual levels to the optimal ones would yield a customer welfare gain of $£ 48-144$ million. This improvement in quality would cost about £23-57 million, which represent an increase of $13-32 \%$ in total cost for each utility. Overall the social welfare would be higher as the social welfare gains are valued between $£ 25$ and 87 million. ${ }^{28}$

Table 5. Simulation results: Optimal quality levels (averages for 12 utilities).

\begin{tabular}{ccccc}
\hline Variable & Units & $\mathbf{1 0 0 \%}$ WTP & $\mathbf{7 5 \%}$ WTP & $\mathbf{5 0 \%}$ WTP \\
\hline WTP & $£ /$ min & 1.92 & 1.44 & 0.96 \\
Marginal Cost & $£ /$ min & 0.25 & 0.25 & 0.25 \\
\hline Actual CML & Million minutes & 161.2 & 161.2 & 161.2 \\
Optimal CML & Million minutes & 80.2 & 69.8 & 53.5 \\
\% Reduction CML & Percentage & $45.5 \%$ & $39.0 \%$ & $29.1 \%$ \\
\hline Customer gains & $£$ million & 143.7 & 94.01 & 48.32 \\
Additional costs & $£$ million & 56.5 & 40.54 & 22.90 \\
Welfare gains & $£$ million & 87.2 & 53.47 & 25.42 \\
\hline
\end{tabular}

In addition, the estimated marginal costs allow us to measure the effect on welfare of the quality improvements in the UK. The simulation results using the original WTP are shown in Table 6. Similar conclusions stem from the adjusted WTPs. The average quality improvement in our sample was about $9.1 \%$ from 1995/6 to $2002 / 3$, which represent one fifth of the optimal reduction in customer minute lost. This improvement has yielded a customer welfare gain of 43 million of pounds, which represents $30 \%$ of the potential customer welfare gains. This improvement in quality has cost about 10 million pounds, which represents a $5.6 \%$ of utilities total costs. Overall, the social welfare has increased in 33 million of pounds.

Table 6. Simulation results: Welfare gains in period 1995/96-2002/3 (averages for 12 utilities).

\begin{tabular}{ccccc}
\hline Variable & Units & $\begin{array}{c}\text { Potential } \\
\text { gains }\end{array}$ & $\begin{array}{c}\text { Observed } \\
\text { performance }\end{array}$ & Difference \\
\hline $\begin{array}{c}\text { \% Reduction } \\
\text { CML }\end{array}$ & Percentage & $45.5 \%$ & $9.1 \%$ & $36.4 \%$ \\
Customer gains & $£$ million & 143.7 & 43.0 & 100.7 \\
Additional costs & $£$ million & 56.5 & 9.9 & 46.6 \\
Welfare gains & $£$ million & 87.2 & 33.1 & 54.1 \\
\hline
\end{tabular}

\footnotetext{
${ }^{28}$ These numbers were obtained assuming constant WTP. The optimal values can be computed as, given other variables to be constant, marginal cost of quality improvement rises with quality (see Figure 9). It should be also noted that the optimal quality of service levels might be overestimated if WTP decreases with quality. This provides an additional justification for carrying out our simulations using an adjusted WTP.
} 


\section{Summary and conclusions}

Quality of service in electricity distribution networks is important for residential, commercial, and industrial customers alike, as many functions of modern society depend on electricity. However, improving upon a given level of quality of service has a cost. The likely effects of incentive regulation on service quality has recently attracted regulators' interest and a number of electricity regulators have made considerable effort to design appropriate regulation mechanisms of quality of service in electricity transmission and distribution networks. In designing qualityincorporated regulatory mechanisms, regulators are faced with the task of determining a market demand curve for service as well as marginal cost of quality improvements.

The main aim of this paper is to estimate econometrically marginal costs of improving quality services in the UK electricity distribution networks. The estimated marginal costs allow us to shed light on the effectiveness of the current UK incentives to improve quality, and to compute optimal quality levels and welfare losses due to sub-optimal quality levels. Our parameter estimates also allow us to measure the effect on welfare of the quality improvements observed in the UK.

In order to achieve these objectives we addressed several issues. First, while accurate information about operational and capital costs and quality services may be available, the marginal cost of quality improvements is not directly observed. For this reason, it is inferred from a previous estimation of the utilities' cost function that reflects both the underlying (physical) technology and the (consequences of the) regulatory environment that conditions utilities' performance. A second issue is that service quality is likely to be negatively correlated with corrective costs, but positively correlated with preventative costs. We attempted to distinguish between both types of cost by including current and (a proxy of) expected levels of quality services as cost determinants. A third issue is to control for the effect of differences among utilities in environmental factors, such as weather, geography, etc. In order to estimate consistently a cost function in the electricity distribution networks, we included weather variables as cost determinants. In addition, we use a fixed-effect type estimator to control for unobserved heterogeneity among firms that might be correlated with the explanatory variables. However, the use of the traditional Fixed Effect estimator in the present application is not inappropriate as many crucial determinants of electricity distribution costs, such as the energy delivered, number of customers, or network length are persistent variables. In order to address this issue we have used the FEVD estimator introduced by Plumper and Troeger (2007).

All elasticities have the expected signs at the sample geometric mean, i.e. the coefficients of network length and network density are positive, the coefficients of energy losses and lead of the customer minutes lost are negative, and the effect of contemporaneous customer minutes lost on cost is also not statistically significant. As in previous studies, we found that technology exhibits decreasing returns to 
scale when expansion requires enlarge the current network to meet extra demand, but increasing returns when network density increases. That is, given network infrastructure, electricity distribution has characteristics of a natural monopoly.

We also found that Totex elasticity of scale increases with size, and that Capex and Opex have a complementary relationship when additional network is required to meet extra demand. However, utilities tend to substitute Capex for Opex when network density increases, indicating that low and high network density utilities adopt different combinations of operating and capital inputs.

The estimated marginal costs suggest that the incentives offered by the UK regulator to reduce their network energy losses are sufficient to yield an improvement in sector performance. However, this improvement is likely not homogeneously distributed among utilities as some of them seem to be insufficiently incentivized to reduce their energy losses. Our results also suggest the existence of different strategies in the UK electricity distribution networks to undertake reductions in network energy losses.

On the other hand, we found that while higher service quality level is associated with higher marginal cost of quality improvement, the marginal cost of improving quality varies considerably across utilities due to their different configuration. Our results hence suggest tailoring the incentives for each utility. The high correlation between incentive rates and estimated marginal costs seems to indicate that they took into account differences in marginal costs to design the incentive schemes in the UK. However, based on our results, we conclude that the UK incentive scheme is not sufficiently strong to incentivise reductions in customer minutes lost as the marginal costs estimated in this paper are much larger than the incentive rates established by the UK regulator. We also found different strategies to tackle reductions in customer minutes lost. Indeed, for low quality utilities, reducing customer minutes lost mostly implies increasing operating cost. In contrast, when service quality is already high, reducing customer minutes lost mostly implies investing in capital inputs.

Finally, we also found that the optimal customer minutes lost is $29-45 \%$ less than the actual levels, based on the willingness to pay estimate relating to the sample period. The observed improvements in quality during the period of this study only represented a $30 \%$ of the potential customer welfare gains, and hence there is still a large range for quality improvements. But, achieving the optimal level of customer minutes lost would represent an increase of $13-32 \%$ in total cost for each utility. Use of more recent data on costs, quality and willingness pay might however give different results, as there appears to have been a significant fall in customer willingness to pay for quality in more recent years. 


\section{References}

Accent (2008), Expectations of DNOs and WTP for improvements in service. A report for OFGEM, July, London: Accent and Ofgem.

Ajodhia, V.S. and Hakvoort, R. (2005). "Economic regulation of quality in electricity distribution networks", Utilities Policy, 13(3), 211-221.

Allan, R.N. and Kariuki, K.K. (1999). "Reliability worth assessments of electrical distribution networks", Quality and Reliability Engineering International, 15, 79-85. Barnett W.A., Kirova, M., and Pasupathy, M. (1996), "Estimating policy invariant deep parameters in the financial sector, when risk and growth matter", Journal of Money Credit and Banking, 27, 1402-1430.

Cronin, F.J., Motluk, S.A. (2007), "How effective are M\&As in distribution? Evaluating the government's policy of using mergers and amalgamations to drive efficiencies into Ontario's LDCs", The Electricity Journal, 20(3), 60-68.

Filippini, M. (1998), "Are municipal electricity distribution utilities natural monopolies?", Annals of Public and Cooperative Economics, 69(2), 157-174.

Giannakis, D., Jamasb, T. and Pollitt, M. (2005). "Benchmarking and incentive regulation of quality of service: an application to the UK electricity distribution networks", Energy Policy, 33(1), 2256-2271.

Guldmann, J.M. (1985), "A disaggregate econometric analysis of electricity distribution capital costs", Energy, 10(5), 601-612.

Huang, Y., Chen, K.H., and Yang, C.H (2010), "Cost efficiency and optimal scale of electricity distribution firms in Taiwan: An application of metafrontier analysis", Energy Economics, 32(1), 15-23.

Jamasb, T. and Pollitt, M. (2001), "Benchmarking and regulation: international electricity experience", Utilities Policy, 9(3), 107-130.

Jamasb, T. and Pollitt, M. (2007), "Incentive regulation of electricity distribution networks: Lessons of experience from Britain", Energy Policy, Vol.35 (12), 61636187.

Jamasb, T., Orea, L., and Pollitt, M. (2010), "Weather Conditions and Performance of Electricity Distribution Networks: A Methodological and Econometric Approach", Cambridge Working Papers in Economics CWPE / Electricity Policy Research Group EPRG 10XX, February, Faculty of Economics, University of Cambridge.

Joskow, P.L. (2006), "Incentive regulation in theory and practice: electricity distribution and transmission networks", Cambridge Working Papers in Economics no. 0607 and Electricity Policy Research Group Working Paper Series no. 0511.

Kariuki, K.K. and Allan, R.N. (1996). "Evaluation of reliability worth and value of lost load." IEE proceedings- Generation, transmission and distribution 143 (2): 171180.

Ofgem (2003), "Developing Monopoly Price Controls", Update Document, Consultation Document, February, Office of Gas and Electricity, Markets, London.

Ofgem (2004), "Executive summary to consumer survey, Consumer expectations of DNOs and WTP for improvements in service report", Accent Marketing \& Research, London.

Ofgem (2010), Electricity Distribution Price Control Final Proposals, London: Ofgem. 
Plumper, T. and Troeger, V.E. (2007), "Efficient Estimation of Time-Invariant and Rarely Changing Variables in Finite Sample Panel Analyses with Unit Fixed Effects", Political Analysis, 15,124-139.

Salvanes, K. and Tjøtta, S. (1998), "A Test for Natural Monopoly with Application to Norwegian Electricity Distribution”, Review of Industrial Organization, 13(6), 669685.

Sappington, D. (2005), "Regulating Service Quality: A Survey”, Journal of Regulatory Economics, 27(2), 123-154.

Tangeras, T. (2009), "Yardstick Competition and Quality", Journal of Economics and Management Strategy, 18(2), 589-613.

Ter-Martirosyan, A. (2003), "The Effects of Incentive Regulation on Quality of Service in Electricity Markets", Working paper, George Washington University.

Wooldridge, J. M. (2002), Econometric Analysis of Cross Section and Panel Data, MIT Press, Cambridge, Massachusetts.

Yatchev, A. (2000), "Scale economies in electricity distribution: a semiparametric analysis", Journal of Applied Econometrics, 15(2), 187-210.

$\mathrm{Yu}$, W., Jamasb, T., and Pollitt, M. (2009a), "Willingness-to-Pay for Quality of Service: An Application to Efficiency Analysis of the UK Electricity Distribution Utilities", Energy Journal, 30(4), 1-48.

Yu, W., Jamasb, T., and Pollitt, M. (2009b), "Does weather explain cost and quality performance? An analysis of UK electricity distribution companies”, Energy Policy, 37(11), 4177-4188. 


\section{APPENDIX}

Table A1. Translog cost function parameter estimates. Dependent variable: InCapex

\begin{tabular}{|c|c|c|c|c|c|c|}
\hline \multirow[b]{2}{*}{ Variable } & \multicolumn{2}{|c|}{ OLS } & \multicolumn{2}{|c|}{$\mathrm{FE}$} & \multicolumn{2}{|c|}{ FEVD } \\
\hline & $\begin{array}{l}\text { paramete } \\
\mathrm{r}\end{array}$ & $\begin{array}{l}\text { robust- } \\
\mathrm{t}\end{array}$ & $\begin{array}{l}\text { paramete } \\
\mathrm{r}\end{array}$ & $\begin{array}{l}\text { robust- } \\
\mathrm{t}\end{array}$ & $\begin{array}{l}\text { paramete } \\
\mathrm{r}\end{array}$ & $\begin{array}{l}\text { robust- } \\
\mathrm{t}\end{array}$ \\
\hline $\ln n_{i t}$ & 1.6560 & 8.3045 & 1.8343 & 1.2732 & 1.6317 & 9.2007 \\
\hline $\ln d_{i t}$ & 1.3917 & 6.2157 & 1.0804 & 1.6628 & 1.4107 & 6.5654 \\
\hline $\ln e_{i t}$ & -0.1584 & -1.2271 & -0.2304 & -1.0092 & -0.2122 & -1.6543 \\
\hline $\ln q_{i t}$ & -0.0793 & -0.7828 & 0.0420 & 0.4606 & 0.0023 & 0.0227 \\
\hline $\ln q_{i t+1}$ & -0.5378 & -4.7037 & -0.3864 & -3.3487 & -0.4655 & -4.8458 \\
\hline $1 / 2\left(\ln n_{i t}\right)^{\wedge}$ & 3.3095 & 2.1820 & 6.9322 & 2.0269 & 3.0068 & 2.0394 \\
\hline $1 / 2\left(\ln d_{i t}\right)^{\wedge}$ & 4.2910 & 2.6745 & 2.5718 & 1.4217 & 3.9116 & 2.3764 \\
\hline $1 / 2\left(\ln e_{i t}\right)^{\wedge} 2$ & -1.1858 & -2.1307 & -1.8420 & -2.3083 & -0.9430 & -1.8655 \\
\hline & \multicolumn{6}{|c|}{$1 / 2(\ln$} \\
\hline$\left.q_{i t+1}\right)^{\wedge}$ & 1.6904 & 3.4367 & 1.3788 & 3.0876 & 1.6825 & 3.7125 \\
\hline $\ln n_{i t} \cdot \ln d_{i t}$ & 1.9745 & 1.4090 & -3.3852 & -1.6723 & 1.3479 & 0.9605 \\
\hline $\ln n_{i t} \cdot \ln e_{i t}$ & 0.7602 & 0.8285 & 2.2896 & 1.8710 & 0.6737 & 0.7800 \\
\hline $\ln n_{i t} \cdot \ln q_{i t}$ & -0.3623 & -0.5236 & 0.6071 & 0.7924 & -0.1704 & -0.2483 \\
\hline $\ln n_{i t} \cdot \ln q_{i t+1}$ & -1.2721 & -1.4902 & -1.2801 & -1.6657 & -1.1844 & -1.4752 \\
\hline $\ln d_{i t} \cdot \ln e_{i t}$ & -0.1580 & -0.2013 & 0.8733 & 0.9222 & -0.0781 & -0.1001 \\
\hline $\ln d_{i t} \cdot \ln q_{i t}$ & 0.9753 & 1.6106 & 1.3199 & 2.2348 & 1.3158 & 2.1876 \\
\hline $\ln d_{i t} \cdot \ln q_{i t+1}$ & -1.4544 & -2.3183 & -1.0576 & -1.7285 & -1.1479 & -2.1873 \\
\hline $\ln e_{i t} \cdot \ln q_{i t}$ & -0.6975 & -2.3640 & -0.9998 & -3.0933 & -0.8231 & -2.8296 \\
\hline $\ln e_{i t} \cdot \ln q_{i t+1}$ & 0.6835 & 1.5040 & 0.6259 & 1.5070 & 0.4923 & 1.2456 \\
\hline $\ln q_{i t} \cdot \ln q_{i t+1}$ & -1.6510 & -3.3329 & -1.2881 & -2.5756 & -1.6619 & -3.5853 \\
\hline $\mathrm{t}$ & -0.0268 & -2.6245 & -0.0312 & -2.1420 & -0.0309 & -3.1380 \\
\hline mate $_{i t}$ & 0.1362 & 4.9184 & 0.1671 & 5.2466 & 0.1789 & 5.3962 \\
\hline dcte $_{i t}$ & 0.0277 & 3.1491 & 0.0059 & 0.4074 & 0.0270 & 3.2227 \\
\hline dhail $_{i t}$ & 0.0010 & 0.2096 & 0.0078 & 1.4268 & 0.0023 & 0.4718 \\
\hline$d t h u_{i t}$ & 0.0086 & 4.7980 & 0.0101 & 4.3459 & 0.0114 & 5.0927 \\
\hline & & 85.736 & & & & 80.832 \\
\hline 1tercept & 4.3555 & 9 & & & 4.3932 & 8 \\
\hline Fixed Effects & & & & & 0.9435 & 2.8413 \\
\hline R-squared & \multicolumn{2}{|c|}{0.7741} & \multicolumn{2}{|c|}{0.5639} & \multicolumn{2}{|c|}{0.7928} \\
\hline
\end{tabular}

